\title{
PI- Controlled PV Fed Fly Back Converter with Enhanced Dynamic Response
}

\author{
A. Wisemin Lins, R. Krishna Kumar
}

\begin{abstract}
Fly back converter is the most popular converter because of its simplicity, low part counts and isolation. It occupies less volume and it saves cost. Fly back converter steps up and step down the voltage with the same polarity. Open loop operation remains insensitive to the input voltage and load variations. Matlab Simulink model for Fly back converter is established using PI controller. Open loop Fly back converter system and closed loop fly back converter systems are simulated and their outcomes are compared. Comparison is done in terms of Rise time, Settling time and steady state error
\end{abstract}

\section{Keywords : Fly back converter, pI controller}

\section{INTRODUCTION}

Due to the depletion of oil resources and regulation of environment the research has been shifted to the renewable energy source. A PV source is considered as an input to the FBC. Fly back converter is the most popular converter which is used for low power applications. The main feature of the Fly back converter is its simplicity, low part counts galvanic isolation ( where the output is completely isolated from the input supply), Multiple output. The output of Fly back converter vary from few watts to 100 watts. Input to the circuit is unregulated DC supply. The fly back converter operates for a wide variation in input. The commonly used switch in the Fly back converter is the MOSFET and the switching frequency is in KHz. The DC-DC converters are used for control the voltage in Electric vehicles, Ceiling excavators, excavator mines etc

\section{Modes of Operation:}

Fly back converter operates in two different modes.(i)Continuous conduction mode (ii) Dis Continuous conduction mode. Continuous conduction mode is used for low voltage, high current applications. Discontinuous conduction mode is used for high voltage, low current applications. The impact of the parasitic elements cannot be ignored while designing the fly back converter as the load resistance becomes small. The Fly back converter steps up and step down the voltages as a transformer while maintaining the same polarity for both input and output. The time taken for a turn on and turn off of a mosfet switch is

Revised Version Manuscript Received on 16 September, 2019. * Correspondence Author

A.Wisemin Lins, EEE Department, Vels Institute Of Science, Technology And Advanced Studies, Chennai, India.Email: wisemineee@gmail.com

Dr.R.Krishna Kumar, Professor/Head EEE Department, Vels Institute Of Science, Technology And Advanced Studies, Chennai, India. Email: hodeee@velsuniv.ac.in less compared to the other switching devices which minimizes the switching losses

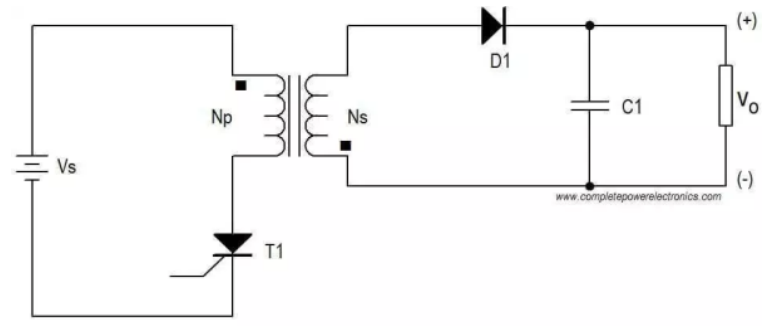

Fig.1.Circuit diagram of Fly back converter

Mode (i)

During mode 1 the mosfet switch is closed.The dotted end of the transformer is considered as positive and the other end is considered as negative. The primary side of the transformer is connected to the positive supply with its dotted end. At the same instant the diode which is connected on the secondary gets blocked because the diode acts in reverse biased condition. The flux established in the primary winding is due to the primary current. The load is provided by the capacitor during the mode 1

$$
\begin{gathered}
\mathrm{V}_{\mathrm{lp}}=\mathrm{V}_{\mathrm{in}} \\
\mathrm{T}_{\text {on }}=\mathrm{DT}_{\mathrm{p}} \\
\mathrm{I}_{\mathrm{LP}}=\frac{\mathrm{V}_{\text {in }}}{\mathrm{L}} \mathrm{T}_{\text {on }}
\end{gathered}
$$

Mode(ii)

When the switch is opened the secondary voltage of the transformer is positive which forward biases the diode allowing the current to flow from the secondary side of the transformer. The energy from the transformer charges the capacitor and the load.

$$
\begin{gathered}
V_{L p}=-\frac{V_{o}}{n} \\
T_{o f f}=(1-D) T_{p}
\end{gathered}
$$

According to the volt second rule average voltage across the inductor at the steady state must be zero.

$$
T_{o n} V_{L p}=D T_{p} V_{i n}
$$

$$
T_{o f f} V_{L P}=(1-D) T_{p}\left(-\frac{V_{o}}{n}\right)
$$




$$
\begin{gathered}
\mathrm{T}_{\text {on }}+T_{\text {off }}=0(\text { volt second rule }) \\
V_{o}=n\left(\frac{D}{1-D}\right) \text { Vin }
\end{gathered}
$$

\section{PI CONTROLLER FED FLYBACK CONVERTER}

The main aim of the controller is that for a reference input, the output should follow the referred input. In industries for the motion control the command signal may be continuously varying according to the dimension of the product. Variation of the output from the input signals results in deceased quality of the product. Therefore it is so important to use the controller by taking the feedback signals from the output. The choice of the gains in the controller is also very important for the precision of motion

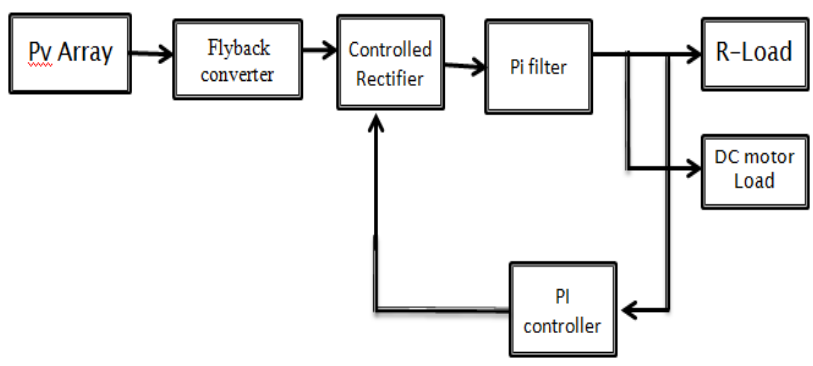

Fig .2.Block diagram of PI controller fed fly back converter

Open loop operation is insensitive to any change in input voltage. To design a PI controller for PV fed fly back converter a closed loop operation is performed. An error signal is derived from the desired value and actual output value. The error signal is processed by using the PI controller and used to control the converter to reduce the steady state error. The proportional and integral gain are determined by using Zeiger Nichols method. The block diagram shown in fig represents the PV fed fly back converter fed by a PI controller. The PI controller output is fed to the PWM generator which controls the duty cycle of the rectifier in the fly back converter to maintain the DC link voltage at a constant value despite of the variations in the input voltage ant loadvariations. "Circuit-diagram of open-loop-Fly-back-converter with disturbance" is delineated in Fig-4. An increase in DC input voltage is considered for PV and battery

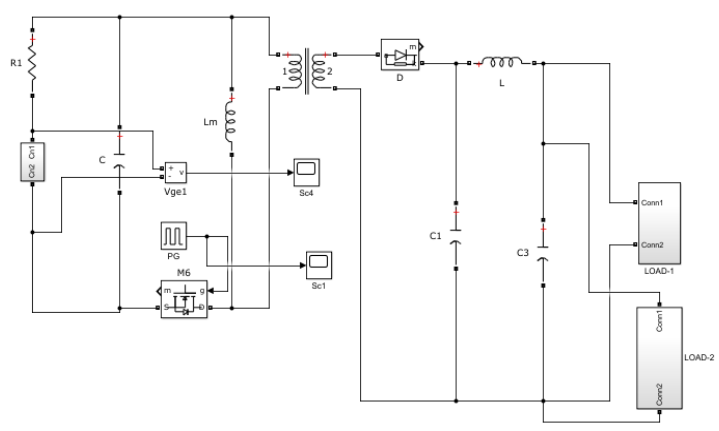

Fig .3. Circuit-diagram of open-loop-FBCS with disturbance

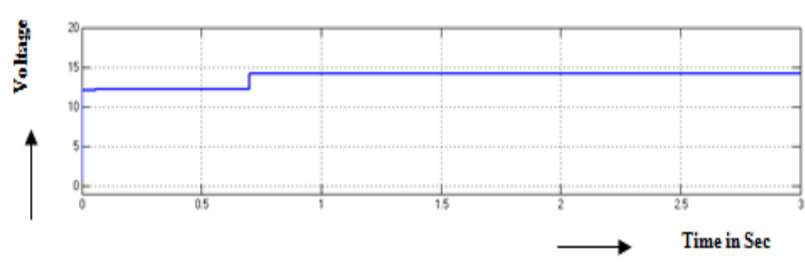

(a)

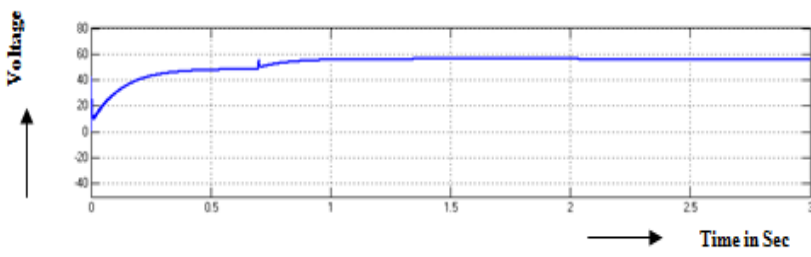

(b)

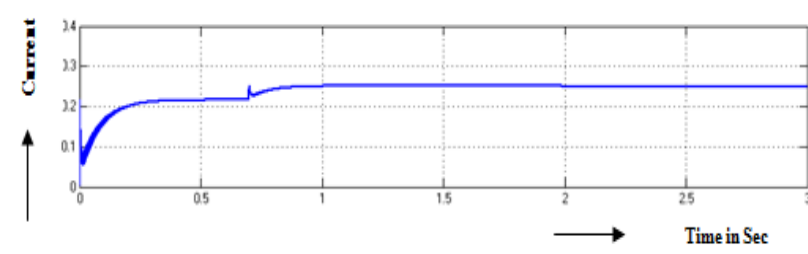

(c)

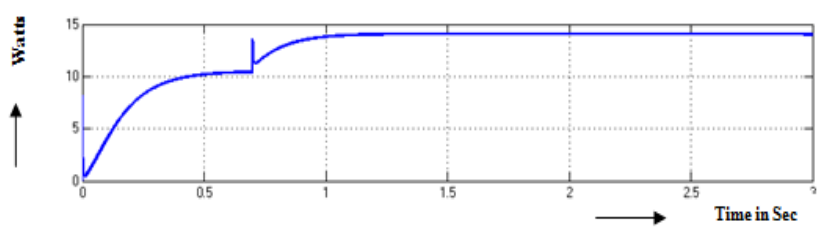

(d)

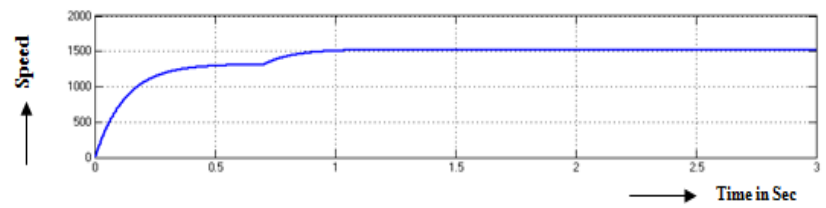

(e)

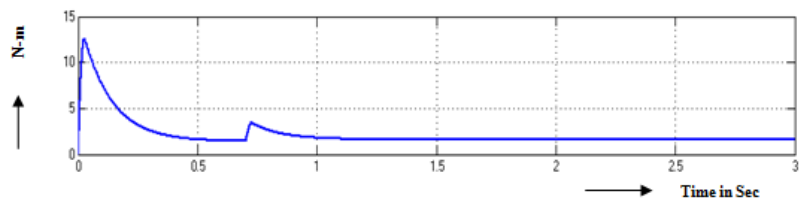

(f)

Fig. 4.(a)input voltage,(b)Output voltage through $\mathrm{R}$ load,(c)Current through R load,(d)Output power,(e)Speed,(f)Torque of fly back converter.

The input voltage, Output voltage, Output power, speed and toque have been plotted against time. From the results it is noted that the input voltage has been raised from $12 \mathrm{~V}$ to $14.5 \mathrm{~V}$ at $\mathrm{t}=0.6 \mathrm{sec}$ and the output voltage has responded to it and it has risen from $48 \mathrm{~V}$ to $59 \mathrm{~V}$ at $\mathrm{t}=0.6 \mathrm{sec}$. There is a increase in the current to 0.24A.Output power has been increased to $14.5 \mathrm{~W}$ from $11 \mathrm{~W}$. Motor speed has also increased from $1200 \mathrm{rpm}$ to $1500 \mathrm{rpm}$ 


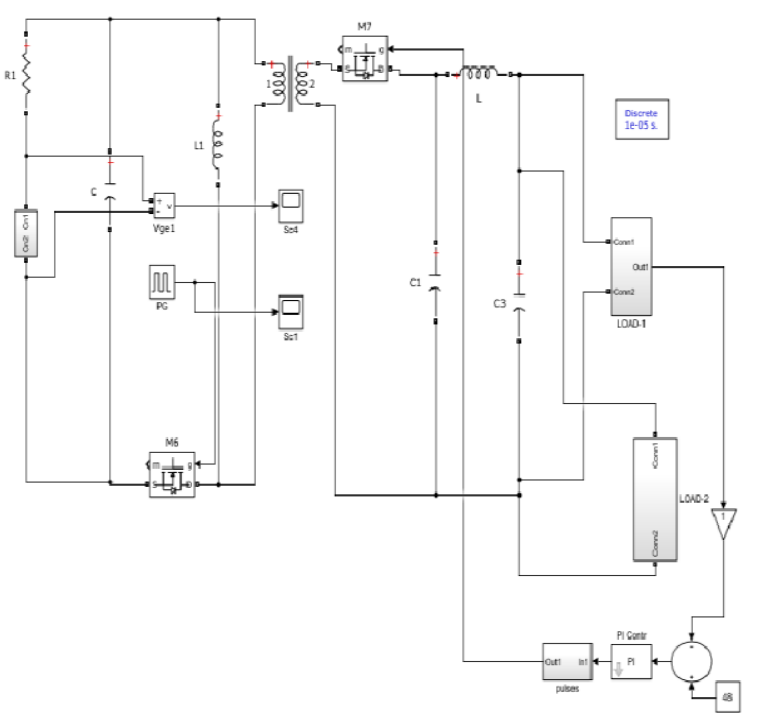

Fig.5.Simulink diagram of PI controller fed fly back converter

The fly back converter is fed with a input voltage of $12 \mathrm{~V}$ and the load is applied to a DC motor load. The reference voltage or the set point is $48 \mathrm{~V}$. An increase in input voltage is done at $0.6 \mathrm{sec}$. The response of the fly back converter is shown in fig. 4

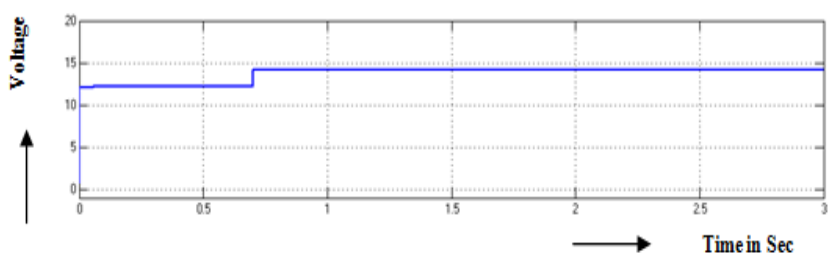

(a)

(b)

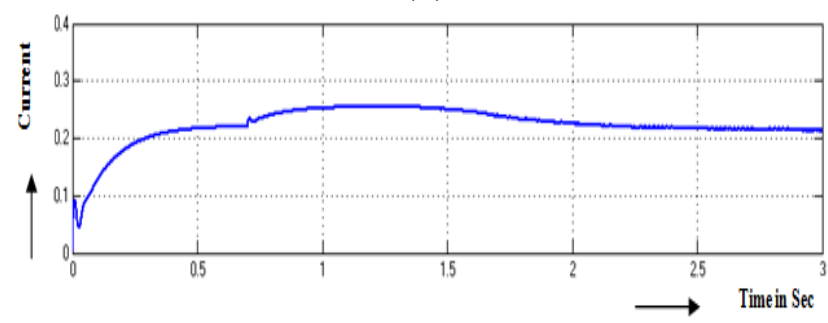

(c)

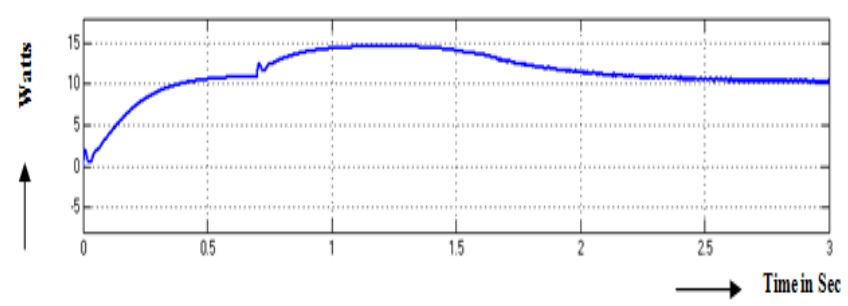

(d)
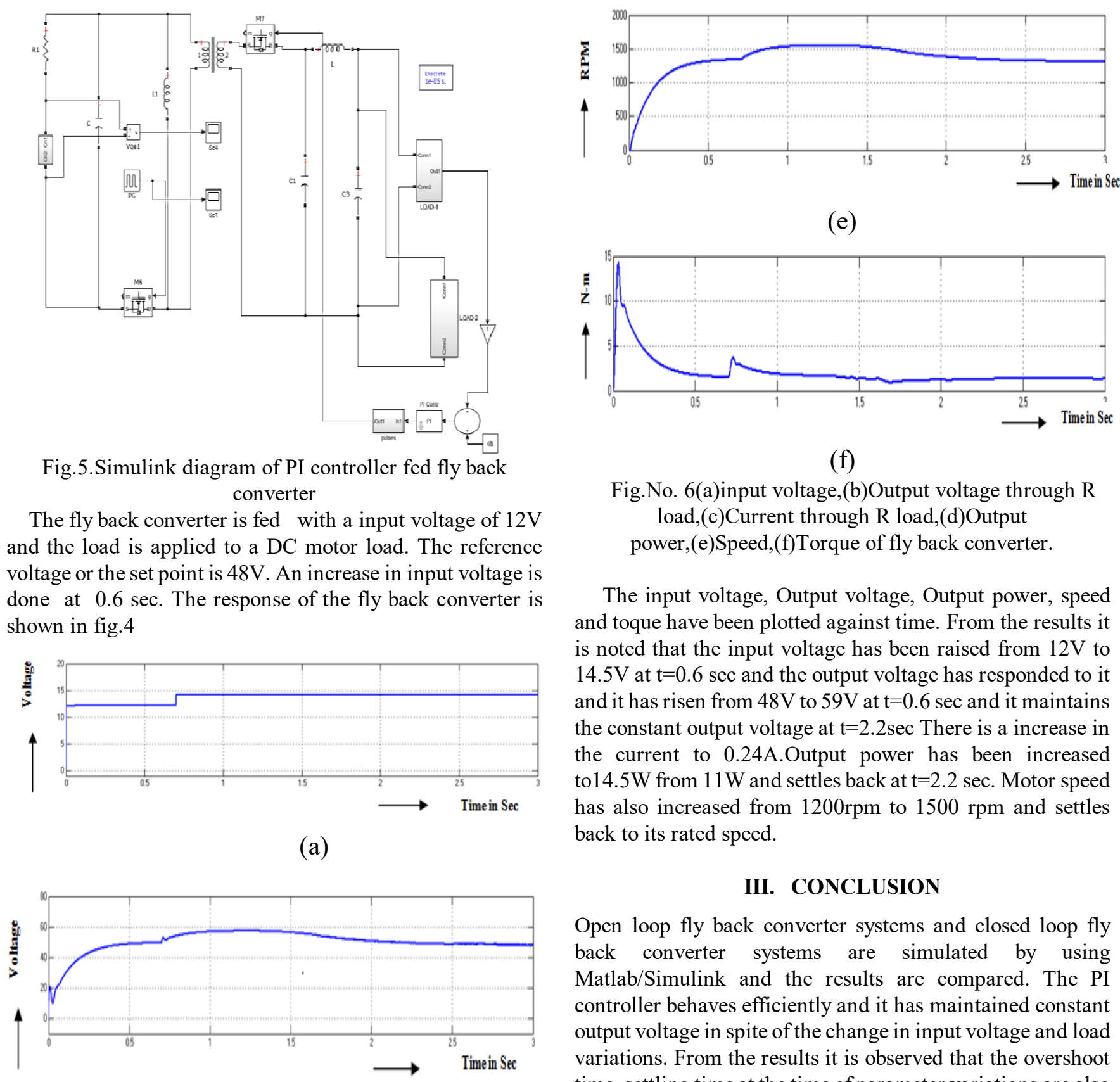

(e)

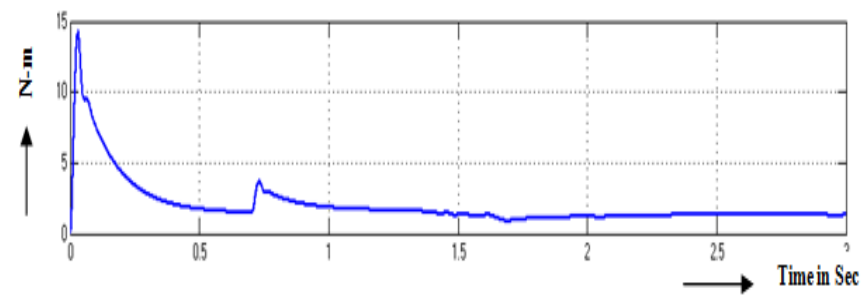

(f)

Fig.No. 6(a)input voltage,(b)Output voltage through $\mathrm{R}$ load,(c)Current through R load,(d)Output power,(e)Speed,(f)Torque of fly back converter.

The input voltage, Output voltage, Output power, speed and toque have been plotted against time. From the results it is noted that the input voltage has been raised from $12 \mathrm{~V}$ to $14.5 \mathrm{~V}$ at $\mathrm{t}=0.6 \mathrm{sec}$ and the output voltage has responded to it and it has risen from $48 \mathrm{~V}$ to $59 \mathrm{~V}$ at $\mathrm{t}=0.6 \mathrm{sec}$ and it maintains the constant output voltage at $\mathrm{t}=2.2 \mathrm{sec}$ There is a increase in the current to $0.24 \mathrm{~A}$. Output power has been increased to $14.5 \mathrm{~W}$ from $11 \mathrm{~W}$ and settles back at $\mathrm{t}=2.2 \mathrm{sec}$. Motor speed has also increased from $1200 \mathrm{rpm}$ to $1500 \mathrm{rpm}$ and settles back to its rated speed.

\section{CONCLUSION}

Open loop fly back converter systems and closed loop fly back converter systems are simulated by using Matlab/Simulink and the results are compared. The PI controller behaves efficiently and it has maintained constant output voltage in spite of the change in input voltage and load variations. From the results it is observed that the overshoot time, settling time at the time of parameter variations are also less. The PI controller controls the parameters near a given reference value. PI controller re moves the steady state error faster and removes the oscillation.

\section{REFERENCES}

1. Amlan Basu., Sumit Mohanty., Rohit Sharma. "Designing of the PD and FOPID controllers using conventional Tuning Techniques" International Conference on Inventive Computation Technologies, August 2016

2. Mitul Kumar.R.Dave, C.K.Dave., "Analysis ofBoost converter using PIcontrol Algorithms"International Journal of Engineering Trends and Technology,Volume 3,Issue2, 2012

3. Kanojiya, R. G., \& Meshram, P. M. (2012). "Optimal tuning of PI controller for speed control of DC motor drive using particle swarm optimization." Proceedings of International Conference on Advances in Power Conversion and Energy Technologies.

4. Alam, M.; Eberle, W.; Gautam, D.S.; Botting, C. A Soft-Switching Bridgeless AC-DC Power Factor Correction Converter. IEEE Trans. Power Electron. 2017, 32, 7716-7726.11

5. Nisha Kasundra, Ankit Kumar, "Design and Simulation of Flyback Converter in MAT LAB

\section{AUTHORS PROFILE}




\section{PI- Controlled PV Fed Fly Back Converter with Enhanced Dynamic Response}

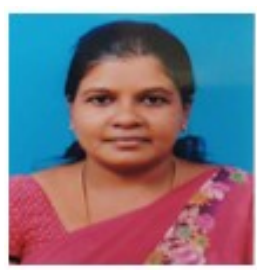

A.Wisemin Lins received B.E degree from the Department of Electrical and Electronics Engineering, from Karunya University, Tamil Nadu, India in 2009. She got M.Tech (Power Electronics) degree from Karunya University, Coimbatore; TamilNadu, India in 2011. She is a Part time Research Scholar at Vels Institute Of Science Technology And Advanced Studies, Chennai, Tamil Nadu, India. Her Area Of research interest is Power Electronics and Drives

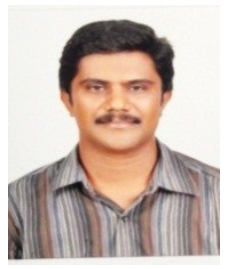

Dr. R. Krishna Kumar received $\mathrm{PhD}$ degree from Anna University, Chennai. He is currently working as a Professor/Head in the department of Electrical and Electronics Engineering, at Vels Institute of Science Technology And Advanced Studies, Chennai, Tamil Nadu, India. He has sixteen years of working experience. $\mathrm{He}$ is a member in SAEINDIA.His area of research interest includes Unmanned Aerial Vehicle (UAV) and Power Electronics and Drives 